\title{
British Adolescents' and Young Adults' Understanding and Reasoning About the Religious and Nonreligious Rights of Asylum-Seeker Youth
}

\author{
Harriet R. Tenenbaum, Kingston University \\ Martin D. Ruck, City University of New York
}

\begin{abstract}
This study examined British young people's understanding of the rights of asylum-seeking young people. Two hundred sixty participants (11-24 years) were read vignettes involving asylum-seeking young people's religious and nonreligious self-determination and nurturance rights. Religious rights were more likely to be endorsed than nonreligious rights. In general, younger participants were more likely than older participants to endorse the rights of asylum-seeking young people. Supporting a social cognitive domain approach, patterns of reasoning varied with the type of right and whether scenarios involved religious or nonreligious issues. Few developmental differences were found regarding participants' reasoning about asylum-seeking young people's religious or nonreligious rights. The findings are discussed with reference to available theory and research on young people's conceptions of rights.
\end{abstract}

When the United Kingdom ratified the Convention on the Rights of the Child (CRC; United Nations General Assembly, 1989), it afforded nurturance and protection rights as well as self-determination or decision-making rights to young people (Ruck \& Horn, 1998). Children's nurturance rights emphasize or stress the provision by society (or some subset of society such as parents or adults) of rights to protect and safeguard children's emotional, psychological, or physical welfare. Hence, nurturance rights must be fulfilled or provided by society or others on behalf of the child. In contrast, self-determination rights, which allow a child to have some measure of control or personal choice in his or her own life, are exercised by the child. However, unlike the majority of countries signing the Convention, the United Kingdom initially entered a reservation enabling it to withhold special protection for refugee and asylum-seeker children (Article 22). Although the reservation was subsequently withdrawn permitting these children the full range of rights and protections under the CRC (Human Rights Joint Committee, 2009), the estimated 82,000 refugee and asylum-seeking minors living in the United Kingdom do not possess the same rights as children with British citizenship (Cemlyn \& Briskman, 2003; Jones, 2001). The United Kingdom's reservation may have stemmed from political and public concern with the asylum-seeking and refugee population in the United Kingdom (e.g., MORI, 2003; Neuberger, 2005; YouGov/Mail on Sunday, 2004). For example, attitudinal surveys conducted with adult samples suggest that views of asylumseekers or refugees are often negative. Asylum seekers and refugees are often perceived as "posing a threat to" British culture or coming to the United Kingdom because they think "it is a soft touch" (i.e., easier to take advantage of compared to other countries; MORI, 2003). Adolescents and emerging young adults in the United Kingdom, like their older adult counterparts (Neuberger, 2005), may consider asylum seekers to be different from themselves and hold negative attitudes toward them. Indeed, recent research suggests that British children (5- to 11-year-olds) view refugee peers more negatively than they do their British peers (Cameron \& Rutland, 2008; Cameron, Rutland, Brown, \& Douch, 2006). Given the growing concern about the rights of immigrants and refugees, this study 

investigated British adolescents' judgments and reasoning about nurturance and self-determination rights of asylum-seeking young people.

Social cognitive domain theory provides a useful guide for the current investigation (for reviews, see Smetana, 2006; Turiel, 2002). This theoretical perspective, commonly referred to as the domain approach, suggests that individuals apply different forms of reasoning across a wide range of social situations. Thus, with regard to thinking about rights, a domain approach would suggest that how children judge and reason about rights is influenced by both the type of right (nurturance or self-determination) and the context or situation in which the right is embedded. For example, using a domain model, Ruck and colleagues (e.g., Ruck, Abramovitch, \& Keating, 1998; Ruck, Peterson-Badali, \& Day, 2002) found that children and adolescents evaluate nurturance rights (e.g., the right to be cared for by parents) differently from self-determination rights (e.g., the right to personal decision making). When reasoning about nurturance rights, young people invoke considerations of parental responsibility and welfare concerns, whereas discussions of self-determination rights tend to correspond to issues of personal choice and autonomy (Helwig, 2006a, 2006b; Ruck \& Peterson-Badali, 2006).

Research conducted from a domain approach has also investigated how children and adolescents reason about civil liberties, such as freedom of religion, which has direct implications for the current investigation. More specifically, Helwig and colleagues (Helwig, 1995, 1997; Helwig \& Turiel, 2002; Lahat, Helwig, Yang, Tan, \& Liu, 2009) found that participants endorse freedom of religion in societal and school contexts believing it to be a universal right by 13 years of age. Young people justify the importance of religion based on notions of selfexpression, autonomy, and on the maintenance of traditions (Helwig, 1997). Endorsement of religious rights extends beyond Western societies with mainland Chinese participants (Lahat et al., 2009) and Druze participants living in Israel (Turiel \& Wainryb, 1998) endorsing freedom of religion. In most of this research, religious rights have been subsumed under and treated as synonymous with self-determination rights. Religious rights may also include nurturance considerations. For example, requiring the provision of special food because of religious dietary restrictions implicates both nurturance and religious rights. How participants coordinate the type of right (i.e., nurturance, self-determination) with whether they simultaneously entail religious requirements has yet to be examined. Such infor- mation may contribute to a domain perspective by further delineating which factors influence participants' reasoning about rights.

In addition, less attention from a domain perspective has been directed toward how young people view the rights of other young people who due to their ethnic group membership or cultural background are more likely to be discriminated against, marginalized or stigmatized compared to their mainstream or majority group counterparts. This would certainly include asylum-seeking and refugee adolescents and young adults. For example, a recent study conducted in the Netherlands indicated that young people more negatively evaluated asylum-seeking peers than Dutch or Moroccan peers living in the Netherlands (Verkuyten \& Steenhuis, 2005). In addition, how young people think about the rights of individuals from nonmainstream groups also provides insight into the beliefs they may hold concerning those who are "different" from them (Ruck, Tenenbaum, \& Sines, 2007). Finally, useful information may be gained from examining the degree to which young people are willing to endorse the rights of individuals from other ethnic or minority groups where such support " "may challenge the status quo or government practices and policies"' (Ruck et al., 2007, p. 688). Hence, the importance of examining British's adolescents' and young adults' attitudes toward the rights of minority groups should not be underestimated.

In one of the few studies examining British adolescents' views of asylum-seeking youth, Ruck et al. (2007) found that British adolescents (early to middle and late adolescents) were more likely to endorse asylum-seeking children's nurturance rights over their self-determination rights. Supporting a social cognitive domain model, participants were more likely to consider issues of empathy and fulfilling basic needs when consider asylum seekers' nurturance rights. In contrast, adolescents were more likely to focus on appeals to personal choice or adherence to authority when discussing asylum seekers' selfdetermination rights. However, findings were limited because of the small sample size $(\mathrm{N}=60$ adolescents) and reliance on only two age groups.

Given that many refugees engage in cultural and religious practices different from and often unfamiliar to mainstream UK society (Lynch \& Cunninghame, 2000), considerations of religious rights may influence the degree to which young people are willing to endorse adolescent and young adult asylum seekers' religious rights and freedoms. Islam has become central in arguments about immigration and ethnic minorities (Verkuyten \& Slooter, 2007). 
In addition, certain Muslim practices have been openly criticized by the media and politicians alike. For example, former Prime Minister, Tony Blair, argued that face veils were a "mark of separation", between Muslims and the UK society (BBC News, 2006). Thus, when asylum seekers wish to engage in particular religious behaviors different from mainstream British society, which tends to be secular or Christian (see CIA World Factbook, 2006), mainstream youth may not perceive such religious practices as rights needing or worthy of protection. Moreover, many of these religious practices, protected by the CRC, may serve to differentiate asylum-seeking youth from their British peers.

Although research has yet to be conducted with British youth, how majority group members view Muslims' freedom of speech and minority rights has been examined in other Western European nations. For example, recent research conducted in the Netherlands found that Dutch adolescents were less tolerant of Muslim than non-Muslims residents wishing to found Muslim only schools or to hold a political demonstration (Verkuyten \& Slooter, 2007, 2008). In addition, over a third of the Dutch adolescents interviewed were not accepting of Muslims' religious practices such as the wearing of a headscarf. These findings suggest that Dutch participants are less supportive of Muslims' political rights and religious practices than those of nonMuslims. Although there is considerable discrimination against Muslims in the Netherlands and the United Kingdom, there are also differences between the two countries in terms of both history and views toward Muslims (Demant, Maussen, \& Rath, 2007; Hussain \& Choudhoury, 2007). Indeed, the history of Muslim immigration into the United Kingdom began over 300 years ago compared to 60 years ago in the Netherlands (Demant et al., 2007; Hussain \& Choudhoury, 2007). Moreover, the political discourse surrounding Muslim immigrants tends to be more negative in the Netherlands than in the United Kingdom (Demant et al., 2007; Hussain \& Choudhoury, 2007). Given these societal similarities as well as differences, it remains an interesting empirical question as to the degree to which British youth hold positive or negative attitudes toward the rights of Muslim asylum seekers.

The final issue considered in the current study was participants' age. Age differences have been found fairly consistently when young people reason about their own rights (for a review, see Peterson-Badali \& Ruck, 2008). In such studies, children tend to support nurturance more than selfdetermination rights when asked to reason about targets matched to them in age (Ruck, Tenenbaum, \& Willenberg, 2011; Ruck et al., 1998). In addition, by early adolescence, young people support selfdetermination rights when thinking about individuals close to their own age (Day, Peterson-Badali, \& Ruck, 2006; Peterson-Badali, Morine, Ruck, \& Slonim, 2004). However, patterns have been less clear when adolescents and young adults judge the rights and freedoms of other individuals. For example, studies examining tolerance of freedom of speech and religious rights in Muslims found no clear age patterns in Dutch 12- to 18-year-old participants (Verkuyten \& Slooter, 2007, 2008). Similarly, in a recent investigation, 8- to 12-year-old Danish children's judgments of exclusion of Muslim children were not found to vary with age (Møller \& Tenenbaum, 2011). Given the lack of clear age difference in past literature when adolescents reason about others, we included participants ranging in age from 11 to 24 years of age to explore more systematically possible age differences. Participants evaluated story characters matched to them in age rather than having all the participants evaluate story characters of a particular age. The mixed findings in the extant literature with regard to age precluded any specific age-related hypotheses.

In sum, the present study examined British adolescents' and young adults' views about the rights of age-matched asylum seekers. To examine whether participants' judgments and reasoning showed differences for nurturance and self-determination rights involving religious considerations, young people were presented with vignettes implicating either religious or nonreligious rights. In this way, the present study contributes to domain theory by examining the degree to which young people coordinate a multiplicity of social knowledge in their judgments and reasoning.

Based on the available research, a number of research predictions were generated. First, based on the research conducted by Ruck et al. (2007), we expected that young people would be more likely to endorse asylum seekers' nurturance than self-determination rights. Second, research conducted in the Netherlands (Verkuyten \& Slooter, 2007, 2008) led us to hypothesize that young people would be less likely to endorse rights at odds with or different from mainstream values. Specifically, we expected that religious rights would be less likely to be supported than nonreligious rights. Third, similar to studies documenting the multifaceted nature of young people's reasoning about nurturance and self-determination rights (e.g., Helwig, 1997, 1998; Ruck et al. 1998; Ruck et al., 2002; Ruck et al., 2007), 
we expected that young people would refer to issues of responsibility and outcomes more for nurturance than self-determination situations. In contrast, we predicted that participants would make appeals to the individual's rights or personal choice more for self-determination than nurturance vignettes. Fourth, given the paucity of research on how majority group members reason about minority group religious rights (cf. Verkuyten \& Slooter, 2007, 2008) we made no predictions as to the types of rationales that would be invoked when discussing religious rights. Finally, we explored whether participants' judgments and reasoning about selfdetermination and nurturance rights varied with respect to whether the situations implicated religious or nonreligious rights.

\section{Method}

\section{Participants}

The sample consisted of 260 participants from the greater London Urban Area ranging in age from 11 to 24 years. The sample was divided into five age groups: 11-12 years (27 males, 29 females), 13-14 years (17 males, 29 females), 15-16 years (24 males, 28 females), 17-18 years (29 males, 35 females), and 19-24 years (15 males, 27 females, recruited from a university in London).

All participants followed the National Curriculum and key stages for England. As much as possible, we tried to split the age groups into naturally occurring groups based on school grades and key stage. All 11- to 14-year-old students were in secondary school in Key Stage 3. The 11- to 12-yearolds were split into two groups based on whether they were in the first 2 years of secondary school (11-12) or the next 2 years (13-14) of secondary school. The 15 - to 16 -year-olds in this sample were in Key Stage 4 enrolled in a General Certificate of Secondary School qualification in various subjects, which is required for higher education. All 17- to 18 -year-olds were in the final 2 years of secondary school (Key Stage 5).

Flyers were sent to state schools to recruit the school-aged participants. Seventy-five percent of parents gave consent for their children to participate. The schools' catchment areas were economically diverse serving low-income (e.g., social housing residents) to upper middle-income children. University students were recruited from a psychology participant pool.

The sample was representative of the greater London Urban Area $(92 \%$ of the UK population and $69.4 \%$ of greater London is White; Home
Office, 2007). All participants were British nationals born in the United Kingdom. The majority, 204 (78.5\%) of young people identified as White British, $5(1.9 \%)$ as mixed race, 17 as (6.5\%) Asian British (mostly of Indian and Pakistani descent), 31 (11.9\%) as Black African or Black Caribbean British, and 3 (1.2\%) as Chinese or East Asian British.

\section{Assessments and Procedures}

Parents of participants under aged 16 provided written consent and their children gave verbal assent before being interviewed. Participants aged 16 and over provided written consent before participation. Participants were interviewed individually in a quiet room or area in their school, college, or university. Eight hypothetical vignettes were presented to each participant. The four nonreligious vignettes had been employed in previous research (Ruck et al., 2007). Half of the vignettes involved asylum-seeker children's nurturance rights while the remaining four concerned self-determination rights. For all of the vignettes, the age of the asylum seeker was matched to the participants' age. Table 1 presents the vignettes used in the study.

Two of the nurturance vignettes pertained to religious rights while the other two concerned secular or nonreligious rights. The nurturance vignettes depicted situations where an asylum seeker either wanted to have a religious nurturance right (e.g., food prepared according to religious belief) or nonreligious nurturance right (e.g., access to parental emotional support) fulfilled possibly in conflict with authority or government practices. A similar dichotomy was employed for self-determination rights, with two concerning religious self-determination rights and the remaining two involving secular or nonreligious self-determination rights. The self-determination vignettes described situations where an adolescent or young adult asylum seeker desired to exercise a religious self-determination right (e.g., right to practice one's religion) or nonreligious self-determination right (e.g., right to personal privacy) possibly in conflict with authority or government practices. In addition, to provide some level of consistency in terms of the contexts examined across the two types of rights (nurturance and self-determination) half of the scenarios dealt with an asylum-seeker in a detention center while the remaining half concerned an asylum-seeker in a school context.

For each vignette, the age and gender of the story character were matched to those of the participants. Research assistants read each vignette to the 
Table 1

Nurturance and Self-Determination Vignettes

Type of right

Nurturance

Self-determination

Religious

Samir /Sameera is an asylum seeker and in his/her religion all food must be prepared in a special way. Samir/Sameera has been sent to a detention center that does not have anyone there who can properly prepare his/her food for him/her. Should the government have to make sure that Samir /Sameera's food is prepared according to his/her religious beliefs?

Husam/Husna is an asylum seeker and in his/her religion, individuals are not allowed to discuss puberty issues with anyone of the opposite gender. Husam/Husna is very upset about a puberty issue and wants to talk to one of the school counselors about it, but there are no school counselors who are male/female. Should the school have to provide a male/female counselor to talk to Husam/Husna about the puberty issue?

\section{Nonreligious}

Nimir /Namar is an asylum seeker and her mum has been put in a detention center for asylum seekers on the other side of the county. Nimir /Namar is very upset and wants to talk to her mum about some problems she is having. Should the government have to make sure that Nimir /Namar can regularly talk to his/her mum over the phone so that she can help Nimir /Nimar with his/her problems? ${ }^{a}$

Rakin/Rahmah and his parents are asylum seekers who have just arrived in the United Kingdom. They do not have enough money to pay for the school uniform that Rakin/Rahmah needs for the school he/she will be attending. Should the school have to pay for the school uniform for Rakin/Rahmah when his family cannot afford to pay for one? ${ }^{a}$
Iman /Iman is an asylum seeker and has arrived in the United Kingdom without his/her parents. He/she has been placed in a detention center and wants to be able to practice his/her religion. He/she is the only person in the detention center from that religion so the government does not want to allow Iman /Iman to practice his/her religion. Should Iman/Iman be able to practice his/her religion in the detention center? Malik/Malika is an asylum seeker and in his/her religion males /females must cover their hair out of modesty when in the company of the opposite gender. Malik's /Malika's teacher says that a headscarf is not part of the official school uniform and so they are not allowed to be worn at school. Should Malik/ Malika be able to wear his/her headscarf at school?

Alim/Alima is an asylum seeker and has arrived in the United Kingdom without his/her parents. Alim/Alima wants to live in London but the government says that he/she has to live in Kent. Should Alim/Alima be able to choose which part of the country he/she wants to live in? ${ }^{\mathrm{a}}$

Tamir /Talah is an asylum seeker and is told by the school that because he/she is not a regular student he/she must carry his/her school ID card with him/her at times while at school. Tamir/Talah does not want to carry the school ID card with him/her. Should Tamir/Talah be able to choose whether or not to carry the ID card while at school? ${ }^{a}$

${ }^{\mathrm{a}}$ Used in Ruck, Tenenbaum, and Sines (2007).

participants. After the presentation of each vignette, participants were asked whether the story character should be allowed to exercise the right in question using a 5-point scale ranging from not at all ()2) to very much (2). In addition, participants were asked to provide a rationale or justification for their response. Probes were used to help participants clarify their specific responses and thinking (e.g., "Can you explain what you mean by that?" “Tell me a little more about that."'). All interviews were audio recorded and transcribed. The order of presentation of the vignettes was counterbalanced.

\section{Coding and Reliability}

Based in part on past research (Helwig, 1997, 1998; Ruck et al., 2002; Ruck et al., 2007) and a reading of the interviews, a justification coding system was developed. Multiple justifications were permitted. Only those justifications comprising 10\% or more of responses for each vignette were analyzed. Participants' justifications were coded according to the categories summarized in Table 2 .

The coding system included categories employed in previous research, such as references to the duty of parents to protect their children's well-being (parental responsibility/care). Appeals to individuals' rights and personal choice were also included (individual rights / personal choice). References to the mandates of authority figures and rules encompassed appeals to authority, laws, or rule obedience (authority/rules). Three categories of special interest for the current study included: references to respecting the beliefs of asylum seekers or immigrants 
Table 2

Justification Categories

\begin{tabular}{|c|c|}
\hline Category & Description (and examples) \\
\hline $\begin{array}{l}\text { Parental } \\
\text { responsibility/ } \\
\text { care }\end{array}$ & $\begin{array}{l}\text { Reference to responsibility, protection, and } \\
\text { care as it relates to parents (e.g., 'It's the } \\
\text { parents' responsibility to take care of their } \\
\text { children') }\end{array}$ \\
\hline $\begin{array}{l}\text { Rights / } \\
\text { personal choice }\end{array}$ & $\begin{array}{l}\text { Reference to the individual's rights, } \\
\text { autonomy, or personal choice to make } \\
\text { decisions (e.g., 'Everyone should have } \\
\text { the right to live where they want”') }\end{array}$ \\
\hline Authority/rules & $\begin{array}{l}\text { Reference to authority and regulations, } \\
\text { laws and following rules (e.g., "It's } \\
\text { important to follow the school rules"') }\end{array}$ \\
\hline $\begin{array}{l}\text { Respecting } \\
\text { customs/beliefs }\end{array}$ & $\begin{array}{l}\text { Reference to respecting the asylum seekers } \\
\text { or immigrants customs, traditions or } \\
\text { beliefs (e.g., “They should respect her } \\
\text { beliefs"”) }\end{array}$ \\
\hline $\begin{array}{l}\text { Practicality/ } \\
\text { alternatives }\end{array}$ & $\begin{array}{l}\text { Reference to practical issues or alternatives } \\
\text { to solve the situation (e.g., “They should } \\
\text { let him have the uniform then he can earn } \\
\text { the money and pay them back") }\end{array}$ \\
\hline $\begin{array}{l}\text { Indebtedness/ } \\
\text { gratitude }\end{array}$ & $\begin{array}{l}\text { Reference to the fact that asylum seekers } \\
\text { should be indebted, grateful, or thankful } \\
\text { for being allowed in the country } \\
\text { (e.g., "They are lucky to be here so they } \\
\text { should be grateful to us") }\end{array}$ \\
\hline $\begin{array}{l}\text { Outcomes/ } \\
\text { consequences }\end{array}$ & $\begin{array}{l}\text { Reference to general positive or negative } \\
\text { aspect of the situation (e.g., "He will get } \\
\text { in trouble if he does that") }\end{array}$ \\
\hline
\end{tabular}

(respecting customs / beliefs), a focus on the practical issues or alternatives with regard to providing or exercising the right in question (practicality/alternatives), and references to the individual or child being indebted or expressing gratitude for asylum in the host county (indebtedness / gratitude). Finally, a category involving references to the positive or negative outcomes associated with the situation (outcomes/consequences) was included. Previous research has shown that references to outcomes and consequences were associated with children's and adolescents' thinking about both nurturance and self-determination rights (Ruck et al., 2002).

Interrater agreement between the first author and a trained research assistant who was blind to the hypotheses was calculated on a randomly selected 21\% (60 transcripts) of the protocols. Uncertainties or discrepancies in the coding were resolved through discussion. Cohen's kappa ( $\mathbf{K}$ ) was calculated as a measure of interrater agreement. Interrater agreement ranged from .67 to .94 with the following kappa coefficients for individual codes: parental responsibility/care, $\mathbf{K}=.67$; rights $/$ personal choice, $\quad \mathbf{K}=.94$; authority / rules, $\quad \mathbf{K}=.68$; respecting customs / beliefs, $\mathbf{K}=.82$; practical considerations, $\mathbf{K}=.75$; indebtedness/ gratitude, $\mathbf{K}=.87$; and outcomes, $\mathbf{K}=.88$.

\section{Results}

For each of the major variables of interest, results are presented separately for endorsements and justifications. An endorsement score was calculated by computing the mean endorsement from -2 to 2 of the two vignettes for each of the four kinds of rights (i.e., religious nurturance, religious self-determination, nonreligious nurturance, nonreligious self-determination). To create the reasoning variables, we combined the number of times that each reasoning category was used in the two vignettes for each of the four kinds of rights (i.e., religious nurturance, nonreligious nurturance, religious selfdetermination, nonreligious self-determination). Scores could range from 0 to 2. Preliminary analyses indicated no gender or context (i.e., detention center or school) effects; therefore, these factors were excluded from all subsequent analyses. Where significant effects are indicated, Bonferroni post hoc tests were carried out by dividing the alpha by the number of tests conducted for each analyses. Finally, only significant main effects and interactions are reported.

\section{Endorsements}

A 2 (type of right: nurturance, self-determination) $\times 2$ (religious: religious, nonreligious) $\mathrm{x}$ 5 (age groups) mixed-design analysis of variance (ANOVA) was conducted. Type of right and religiousness served as repeated measures factors while age served as a between-participants factor. All significant main effects and interactions related to the hypotheses are discussed next.

As predicted, there was a main effect of type of right, $\mathrm{F}(1,255)=14.78, \mathrm{p}=.0001, \mathrm{~g}_{\mathrm{p}}^{2}=.06$, with participants more likely to endorse nurturance $(\mathrm{M}=1.04, \mathrm{SD}=0.79)$ than self-determination $(\mathrm{M}=$ $0.83, \mathrm{SD}=0.83$ ) rights. Similarly, there was a main effect of the religious nature of the right, $\mathrm{F}(1$, $255)=37.69, \mathrm{p}=.0001, \mathrm{~g}_{\mathrm{p}}{ }^{2}=.13$. Contrary to expectations, young people were more likely to endorse religious $(\mathrm{M}=1.11, \mathrm{SD}=0.83)$ than nonreligious $(\mathrm{M}=0.76, \mathrm{SD}=0.85)$ rights.

These effects were qualified by a significant Type of Right $x$ Religiousness interaction effect, $F(1,255)$ $=333.04, \mathrm{p}=.0001, \mathrm{~g}_{\mathrm{p}}{ }^{2}=.57$. Bonferroni tests using .008 as a corrected p-value (.05 divided by the six contrasts) indicated that participants endorsed 
asylum-seeking young people's nonreligious nurturance rights $(\mathrm{M}=1.38, \quad \mathrm{SD}=0.86)$ as much as their religious self-determination $(\mathrm{M}=1.52, \mathrm{SD}=$ $1.52)$ rights, $\mathrm{F}(1,259)=4.15, \mathrm{p}=.04, \mathrm{~g}_{\mathrm{p}}{ }^{2}=.02$. However, religious nurturance rights $(\mathrm{M}=0.70$, $\mathrm{SD}=1.20$ ) were endorsed to a lesser extent than nonreligious nurturance rights, $F(1,259)=61.49$, $\mathrm{p}=.0001, \mathrm{~g}_{\mathrm{p}}{ }^{2}=.19$, or religious self-determination rights, $\mathrm{F}(1,259)=107.97, \mathrm{p}=.0001, \mathrm{~g}_{\mathrm{p}}^{2}=.29$. Nonreligious self-determination rights $(\mathrm{M}=0.13, \mathrm{SD}=$

1.27) were endorsed to a lesser extent than religious nurturance rights, $\mathrm{F}(1,259)=217.51, \mathrm{p}=.0001$, $\mathrm{g}_{\mathrm{p}}{ }^{2}=.46$, nonreligious nurturance rights, $\mathrm{F}(1,259)$ $=256.15, \quad \mathrm{p}=.0001, \mathrm{~g}_{\mathrm{p}}{ }^{2}=.50, \quad$ or religious selfdetermination rights, $\mathrm{F}(1,259)=473.15, \mathrm{p}=.0001$, $\mathrm{g}_{\mathrm{p}}^{2}=.65$.

In addition, there was a main effect of age, $\mathrm{F}(4$, 255) 4.18, $\mathrm{p}=.003, \mathrm{~g}_{\mathrm{p}}{ }^{2}=.06$. Follow-up Bonferroni tests indicated that the 11 - to 12 -year-olds $(\mathrm{M}=1.17$, $\mathrm{SD}=0.54$ ) were more likely to endorse the four kinds of rights combined than the 15- to 16-year-olds $(\mathrm{M}=0.80, \quad \mathrm{SD}=0.68), \quad \mathrm{F}(1,106)=10.25, \quad \mathrm{p}=.002$, $\mathrm{g}_{\mathrm{p}}{ }^{2}=.09 ; 17$ - to 18 -year-olds $(\mathrm{M}=0.80, \mathrm{SD}=0.61)$, $\mathrm{F}(1,118)=12.34, \mathrm{p}=.001, \mathrm{~g}_{\mathrm{p}}{ }^{2}=.10$; or 19 - to $24-$ year-olds $(\mathrm{M}=0.80, \quad \mathrm{SD}=0.67), \mathrm{F}(1,96)=8.89$, $\mathrm{p}=.004, \mathrm{~g}_{\mathrm{p}}{ }^{2}=.09$, who did not differ from each other in their endorsement ( $F$ values ranged from .001 to .007). In addition, 13- to 14-year-olds $(\mathrm{M}=1.08, \mathrm{SD}=0.74)$ did not differ from the other age groups in their endorsement of all four kinds of asylum-seeking children's rights (F values ranged from 3.25 to 4.70 ).

There was also an Age - Type of Right - Religiousness interaction effect, $F(4,255)=7.26$, $\mathrm{p}=.0001, \mathrm{~g}_{\mathrm{p}}^{2}=.10$. Means are displayed in Table 3 . Follow-up ANOVAs using a p value of .005 were conducted for each type of right separately. First, there was a significant age effect for religious nurturance rights, $\mathrm{F}(4,255)=4.27, \mathrm{p}=.002, \mathrm{~g}_{\mathrm{p}}{ }^{2}=.06$. Eleven- to 12-year-olds endorsed more religious nurturance rights than the 17- to 18-year-old group, $\mathrm{F}(1,118)=15.56, \mathrm{p}=.0001, \mathrm{~g}_{\mathrm{p}}{ }^{2}=.12$. The other age groups did not differ from each other (F values ranged from .12 to 7.50). Similarly, there was an age effect for nonreligious self-determination rights, $\mathrm{F}(1,259)=6.21, \mathrm{p}=.0001, \mathrm{~g}_{\mathrm{p}}{ }^{2}=.09$. Eleven- to 12-yearold children endorsed more nonreligious self-determination rights than both 17 - to 18 -year-olds, $\mathrm{F}(1$, 118) $=8.85, \mathrm{p}=.004, \mathrm{~g}_{\mathrm{p}}{ }^{2}=.07$, and 19- to-24-yearolds, $\mathrm{F}(1,96)=16.87, \mathrm{p}=.0001, \mathrm{~g}_{\mathrm{p}}^{2}=.15$. In addition, the 13- to 14-year-old group endorsed religious self-determination rights more than did the 19- to 24year-old age group, $\mathrm{F}(1,86)=15.12, \mathrm{p}=.0001$, $\mathrm{g}_{\mathrm{p}}{ }^{2}=.15$. The other age groups did not differ from each other (F values ranged from .62 to 6.79). There were no significant age effects for participants' endorsement concerning nonreligious nurturance, $\mathrm{F}(1,259)=.60, \mathrm{p}=.67$, or religious self-determination rights, $\mathrm{F}(1,259)=3.14, \mathrm{p}=.02$, with the protected p value.

\section{Justifications}

To examine the categories of reasoning that participants employed, a 2 (type of right: nurturance, self-determination) - 2 (religious: religious, nonreligious) - 5 (age groups) - 7 (justification category: parental responsibility/care, rights / personal choice, authority/rules, respecting customs/beliefs, practical considerations, indebtedness / gratitude, outcomes / consequences) mixed-design ANOVA was conducted. Type of right, religiousness, and justification categories served as repeated measures factors while age served as a between-participants factor. All main effects and interaction effects related to the hypotheses are discussed next. Table 4 presents the mean usage of justifications by type of vignette.

Justifications relating to nurturance and self-determination rights. A number of main effects and two-way interaction interactions of interest were significant.

Table 3

Mean Endorsement Scores by Type of Vignette and Age

\begin{tabular}{lllllll}
\hline & & \multicolumn{3}{c}{ Nurturance } & & \multicolumn{2}{c}{ Self-determination } \\
\cline { 3 - 5 } Age group & $\mathrm{n}$ & Religious & Nonreligious & & Religious & Nonreligious \\
\hline $11-12$ & 56 & $1.13(.97)$ & $1.34(.83)$ & $1.64(.62)$ & $.59(1.31)$ \\
$13-14$ & 46 & $.87(1.13)$ & $1.35(.88)$ & $1.61(.92)$ & $.50(1.13)$ \\
$15-16$ & 52 & $.52(1.28)$ & $1.42(.81)$ & $1.17(1.03)$ & $.08(1.19)$ \\
$17-18$ & 64 & $.30(1.26)$ & $1.48(.71)$ & & $1.52(.79)$ & $.10(1.24)$ \\
$19-24$ & 42 & $.79(1.19)$ & $1.24(1.13)$ & & $1.69(.75)$ & $.48(1.23)$ \\
\hline
\end{tabular}

Note. Standard deviations are in parentheses. Scores ranged from -2 (disagree strongly that the right should be granted) to 2 (agree strongly that the right should be granted). 
Table 4

Mean Usage of Justifications by Type of Right

\begin{tabular}{|c|c|c|c|c|}
\hline \multirow[b]{2}{*}{ Justification category } & \multicolumn{2}{|c|}{ Nurturance } & \multicolumn{2}{|c|}{ Self-determination } \\
\hline & Religious & Nonreligious & Religious & Nonreligious \\
\hline Parental responsibility/care & $.02_{\text {c }}(.15)$ & $.38_{\mathrm{b}} \quad(.52)$ & $.02_{\mathrm{d}}(.15)$ & $.01_{\mathrm{e}} \quad(.11)$ \\
\hline Rights /personal choice & $.53_{a}(.62)$ & $.54_{\mathrm{a}, \mathrm{b}}(.67)$ & $1.21_{\mathrm{a}}(.75)$ & $.79_{\mathrm{a}}(.66)$ \\
\hline Authority/rules & $.22_{\mathrm{b}}(.45)$ & $.23_{\mathrm{c}} \quad(.47)$ & $.11_{\mathrm{c}}(.31)$ & $.46_{\mathrm{b}} \quad(.60)$ \\
\hline Respecting customs/beliefs & $.25_{\mathrm{b}}(.49)$ & $.00_{\mathrm{d}} \quad(.00)$ & $.44_{\mathrm{b}} \quad(.62)$ & $.00_{\mathrm{e}} \quad(.06)$ \\
\hline Practicality/alternatives & $.42_{a}(.57)$ & $.25_{\mathrm{c}} \quad(.46)$ & $.07_{\mathrm{c}, \mathrm{l}}(.25)$ & $.12_{\mathrm{d}} \quad(.34)$ \\
\hline Indebtedness/gratitude & $.05_{c}(.22)$ & $.02_{\mathrm{d}} \quad(.16)$ & $.01_{\mathrm{d}}(.09)$ & $.30_{\mathrm{c}} \quad(.47)$ \\
\hline Outcomes/consequences & .58 a $(.68)$ & $.63_{\mathrm{a}} \quad(.68)$ & $.42_{\mathrm{b}} \quad(.63)$ & $.45_{b, c}(.58)$ \\
\hline
\end{tabular}

Note. Standard deviations are in parentheses. Values in each column with different subscripts are significantly different from one another using Bonferonni tests.

There was a significant Type of Right - Justification Category interaction, $\mathrm{F}(4,1146)=72.93, \mathrm{p}=.0001$, $\mathrm{g}_{\mathrm{p}}{ }^{2}=.22$. Specifically, references to outcomes were used more frequently for nurturance $(M=1.23$, $\mathrm{SD}=1.05)$ than self-determination $(\mathrm{M}=0.87, \mathrm{SD}=$ $0.95)$ vignettes, $\mathrm{F}(1,259)=23.36, \mathrm{p}=.0001, \mathrm{~g}_{\mathrm{p}}^{2}=.08$. In addition, parental responsibility was used more frequently for nurturance $(\mathrm{M}=0.40, \mathrm{SD}=0.54)$ than self-determination $(\mathrm{M}=0.03, \mathrm{SD}=0.18)$ scenarios, $\mathrm{F}(1,259)=118.02, \mathrm{p}=.0001, \mathrm{~g}_{\mathrm{p}}{ }^{2}=.31$. Finally, references to practical considerations or alternatives were used more frequently for nurturance $(\mathrm{M}=0.67$, $\mathrm{SD}=0.77)$ than self-determination $(\mathrm{M}=0.18, \mathrm{SD}=$ 0.45 ) vignettes, $\mathrm{F}(1,259)=81.13, \mathrm{p}=.0001, \mathrm{~g}_{\mathrm{p}}{ }^{2}=.24$.

In contrast, participants made more frequent appeals to the asylum-seeker child's individual rights or personal choice for self-determination $(\mathrm{M}=1.96$, $\mathrm{SD}=1.09)$ than nurturance $(\mathrm{M}=1.03, \mathrm{SD}=0.95)$ vignettes, $\mathrm{F}(1,259)=160.00, \mathrm{p}=.0001, \mathrm{~g}_{\mathrm{p}}{ }^{2}=.38$. Additionally, participants were more likely to suggest that young asylum seekers should be indebted or grateful for being in the country when considering self-determination $(\mathrm{M}=0.31, \mathrm{SD}=0.49)$ than nurturance $(\mathrm{M}=0.07, \mathrm{SD}=0.31)$ vignettes, $\mathrm{F}(1,259)=55.12$, $\mathrm{p}=.0001, \mathrm{~g}_{\mathrm{p}}{ }^{2}=.18$. Finally, references to respecting asylum seekers' customs and belief were used more often for self-determination $(\mathrm{M}=45$, $\mathrm{SD}=0.63)$ than nurturance $(\mathrm{M}=0.25, \mathrm{SD}=0.49)$ vignettes, $\mathrm{F}(1$, 259) $=20.40, \mathrm{p}=.0001, \mathrm{~g}_{\mathrm{p}}{ }^{2}=.07$.

Justifications comparing religious and nonreligious rights. As expected, there was also a significant Religiousness - Justification Category interaction effect, $\mathrm{F}(4,1093)=47.25, \mathrm{p}=.0001, \mathrm{~g}_{\mathrm{p}}{ }^{2}=.16$. There were interesting differences in the various justification categories employed for religious and nonreligious situations. To begin, participants were more likely to refer to the asylum seekers' individual rights and personal choice for religious $(\mathrm{M}=1.73$,
$\mathrm{SD}=1.13)$ than nonreligious $(\mathrm{M}=1.33, \mathrm{SD}=1.03)$ situations, $\mathrm{F}(1,259)=23.34, \mathrm{p}=.0001, \mathrm{~g}_{\mathrm{p}}{ }^{2}=.08$. In addition, respecting asylum seekers' customs and beliefs was more likely to be mentioned for religious $(\mathrm{M}=0.69$, $\mathrm{SD}=0.88)$ than nonreligious vignettes $(\mathrm{M}=0.00, \mathrm{SD}=0.06), \mathrm{F}(1,259)=161.39$, $\mathrm{p}=$ $.0001, \mathrm{~g}_{\mathrm{p}}{ }^{2}=.38$.

Participants were more likely to indicate that asylum-seeking story characters should be indebted or grateful for being allowed to be in the United Kingdom when providing rationales for nonreligious $(\mathrm{M}=0.32, \mathrm{SD}=0.51)$ than religious $(\mathrm{M}=$ 0.06, $\mathrm{SD}=0.26)$ vignettes, $\mathrm{F}(1,259)=69.05, \mathrm{p}=$ $.0001, \mathrm{~g}_{\mathrm{p}}{ }^{2}=.21$. In addition, respondents were also more likely to consider parental responsibility and care when discussing nonreligious $(\mathrm{M}=0.39$, $\mathrm{SD}=$ $0.53)$ than religious $(\mathrm{M}=0.04, \mathrm{SD}=0.25)$ vignettes, $\mathrm{F}(1,259)=94.26, \mathrm{p}=.0001, \mathrm{~g}_{\mathrm{p}}{ }^{2}=.27$. Finally, justifications involving authority and rules were more likely to be considered in nonreligious $(\mathrm{M}=0.70$, $\mathrm{SD}=0.78)$ than religious $(\mathrm{M}=0.32, \quad \mathrm{SD}=0.56)$ vignettes, $\mathrm{F}(1,259)=48.11, \mathrm{p}=.0001, \mathrm{~g}_{\mathrm{p}}{ }^{2}=.16$.

Justification by type of right and religiousness. There was a significant Type of Right - Religiousness Justification Category interaction, $F(5,1177)=33.25$, $\mathrm{p}=.0001, \mathrm{~g}_{\mathrm{p}}{ }^{2}=.12$. To examine which types of reasoning were used most across vignettes, 2 (type of right) - 2 (religious, nonreligious) ANOVAs were conducted for each category of reasoning. Where significant interactions were found, follow-up Bonferonni tests were conducted to examine which justification categories participants used for each type of religious or nonreligious right. To aid in interpretation we only report those justification categories used the most for each kind of religious nurturance, religious self-determination, nonreligious nurturance, and nonreligious self-determination right vignettes. 
To begin, there was a significant interaction effect for justifications involving parental responsibility and care, $\mathrm{F}(1, \quad 259)=110.00, \quad \mathrm{p}=.0001$, $\mathrm{g}_{\mathrm{p}}{ }^{2}=.30$. Follow-up tests revealed that appeals to parental responsibility and care were significantly more likely to be made when discussing nonreligious nurturance vignettes than religious nurturance, $\mathrm{F}(1,259)=113.76, \mathrm{p}=.0001, \mathrm{~g}_{\mathrm{p}}{ }^{2}=.31$; religious self-determination, $\mathrm{F}(1,259)=117.85, \mathrm{p}=$ $.0001, \mathrm{~g}_{\mathrm{p}}{ }^{2}=.31$; or nonreligious self-determination rights, $\mathrm{F}(1,259)=126.53, \mathrm{p}=.0001, \mathrm{~g}_{\mathrm{p}}{ }^{2}=.33$. The other contrasts were not significant with $F$ values ranging from .11 to 1.00 .

Second, there was a significant interaction effect involving individual rights and personal choice, $\mathrm{F}(1,259)=160.00, \mathrm{p}=.0001, \mathrm{~g}_{\mathrm{p}}^{2}=.38$. Post hoc tests indicated that references to the asylum-seeking story characters' rights and personal choice were more likely to be used when considering religious self-determination vignettes than religious nurturance, $\mathrm{F}(1,259)=183.04, \mathrm{p}=.0001, \mathrm{~g}_{\mathrm{p}}^{2}=.41$; nonreligious nurturance, $\mathrm{F}(1,259)=143.41, \mathrm{p}=.0001$, $\mathrm{g}_{\mathrm{p}}{ }^{2}=.36$; or nonreligious self-determination rights, $\mathrm{F}(1,259)=55.49, \mathrm{p}=.0001, \mathrm{~g}_{\mathrm{p}}{ }^{2}=.18$. References to rights and personal choice were more likely used when discussing nonreligious self-determination than religious nurturance, $\mathrm{F}(1,259)=22.12, \mathrm{p}=$ $.0001, \mathrm{~g}_{\mathrm{p}}{ }^{2}=.08$, or nonreligious nurturance rights, $\mathrm{F}(1,259)=22.39, \mathrm{p}=.0001, \mathrm{~g}_{\mathrm{p}}{ }^{2}=.08$; the latter two did not differ from each other, $F(1,259)=.08$, $\mathrm{p}=.78$.

Third, there was a significant interaction effect for use of authority/rules, $F(1,259)=37.35$, $\mathrm{p}=.0001, \mathrm{~g}_{\mathrm{p}}{ }^{2}=.13$. The results of follow-up tests indicated that references to authority/rules were more likely to be used when discussing nonreligious self-determination vignettes than nonreligious nurturance, $\mathrm{F}(1,259)=24.49, \mathrm{p}=.0001, \mathrm{~g}_{\mathrm{p}}{ }^{2}=.09$; religious nurturance, $\mathrm{F}(1,259)=32.32, \mathrm{p}=.0001$, $\mathrm{g}_{\mathrm{p}}{ }^{2}=.11$; or religious self-determination vignettes, $\mathrm{F}(1,259)=81.51, \mathrm{p}=.0001, \mathrm{~g}_{\mathrm{p}}{ }^{2}=.24$. References to authority/rules were made more frequently when discussing nonreligious nurturance, $\mathrm{F}(1,259)=12.79$, $\mathrm{p}=.001, \mathrm{~g}_{\mathrm{p}}{ }^{2}=.05$, and religious nurturance rights, $\mathrm{F}(1,259)=10.70, \quad \mathrm{p}=.001, \quad \mathrm{~g}_{\mathrm{p}}{ }^{2}=.04 ;$ the latter two did not differ from each other, $F(1,259)=26$, $\mathrm{p}=.61$.

Fourth, there was a significant interaction effect for justifications concerning respecting asylumseekers' customs and beliefs, $F(1,259)=18.72$, $\mathrm{p}=.0001, \mathrm{~g}_{\mathrm{p}}{ }^{2}=.07$. Follow-up tests revealed that references to respecting customs and beliefs were used more when discussing religious self-determination vignettes than religious nurturance,
$\mathrm{F}(1,259)=111.45, \mathrm{p}=.0001, \mathrm{~g}_{\mathrm{p}}{ }^{2}=.30$; nonreligious nurturance, $\mathrm{F}(1,259)=131.56, \mathrm{p}=.0001, \mathrm{~g}_{\mathrm{p}}{ }^{2}=.34$; or nonreligious self-determination vignettes, $\mathrm{F}(1$, $259)=129.44, \mathrm{p}=.0001, \mathrm{~g}_{\mathrm{p}}{ }^{2}=.33$. References to respecting customs and beliefs were made more frequently when discussing religious nurturance than nonreligious nurturance, $F(1,259)=67.07$, $\mathrm{p}=.0001, \mathrm{~g}_{\mathrm{p}}{ }^{2}=.21$, or nonreligious self-determination vignettes, $\mathrm{F}(1,259)=65.55, \mathrm{p}=.0001, \mathrm{~g}_{\mathrm{p}}{ }^{2}=.20$; the latter two did not differ from each other, $\mathrm{F}(1$, 259) $=1.00, \mathrm{p}=.32$.

Fifth, a significant interaction was also found for references to practical considerations or alternatives, $\mathrm{F}(1,259)=18.60, \mathrm{p}=.0001, \mathrm{~g}_{\mathrm{p}}{ }^{2}=.07$. Follow-up tests indicated that consideration of practicality or alternatives were used most frequently when discussing nurturance religious vignettes than nurturance nonreligious, $\mathrm{F}(1,259)=14.63, \mathrm{p}=.0001, \mathrm{~g}_{\mathrm{p}}{ }^{2}=.05$; nonreligious self-determination, $\mathrm{F}(1,259)=54.80, \mathrm{p}=$ $.0001, \mathrm{~g}_{\mathrm{p}}{ }^{2}=.18 ; \quad$ or religious self-determination vignettes, $\mathrm{F}(1,259)=79.97, \mathrm{p}=.0001, \mathrm{~g}_{\mathrm{p}}{ }^{2}=.24$. Reference to practicality or alternatives was greater while discussing nonreligious self-determination, $\mathrm{F}(1,259)=15.59, \mathrm{p}=.0001, \mathrm{~g}_{\mathrm{p}}{ }^{2}=.06$, or religious self-determination vignettes, $F(1,259)=33.20$, $\mathrm{p}=.0001, \mathrm{~g}_{\mathrm{p}}{ }^{2}=.11$. Reference to practicality or alternatives did not differ from each other in the latter two types of vignettes, $\mathrm{F}(1,259)=4.17$, $\mathrm{p}=.04$, with the protected probability level of .008 (.05 divided by the six contrasts).

Finally, there was a significant interaction for participants' references to indebtedness and gratitude, $\mathrm{F}(1,259)=101.07, \mathrm{p}=.0001, \mathrm{~g}_{\mathrm{p}}{ }^{2}=.28$. Follow-up tests indicated that suggesting that the asylum-seeking story character should be indebted or grateful to the host country was more likely to occur when discussing nonreligious self-determination vignettes than when discussing nurturance religious, $F(1$, 259) $=70.85, \quad \mathrm{p}=.0001, \quad \mathrm{~g}_{\mathrm{p}}{ }^{2}=.22 ; \quad$ nonreligious nurturance, $\mathrm{F}(1,259)=89.52, \mathrm{p}=.0001, \mathrm{~g}_{\mathrm{p}}{ }^{2}=.26$; or religious self-determination vignettes, $\mathrm{F}(1,259)=$ $105.10, \mathrm{p}=.0001, \mathrm{~g}_{\mathrm{p}}{ }^{2}=.29$. Reference to indebtedness and grateful was used more when discussing religious nurturance than religious self-determination vignettes, $\mathrm{F}(1,259)=11.44, \mathrm{p}=.001, \mathrm{~g}_{\mathrm{p}}{ }^{2}=.04$. With the protected alpha of .008 , there were no other significant contrasts (F values ranged from 1.00 to 4.64). There was no significant interaction effect for the use of outcomes or consequences, $\mathrm{F}(1,259)=.08, \mathrm{p}=.78$.

Age-related patterns. The analysis revealed a significant Type of Right - Religiousness - Age Justification Category interaction, $\mathrm{F}(18,1177)=2.68$, $\mathrm{p}=.0001, \mathrm{~g}_{\mathrm{p}}{ }^{2}=.04$. To examine this interaction, individual one-way ANOVAs with age as the 
independent predictor variable were conducted with a protected $\mathrm{p}$ value of .002 . The number of times each category of reasoning was used separately for the four kinds of vignettes served as the dependent variable. Only two contrasts were significant (the other contrasts had $\mathrm{F}$ values ranging from .17 to 3.85). First, there was a main effect for references to outcome and consequences for religious nurturance vignettes, $\mathrm{F}(4,255)=7.03, \mathrm{p}=.0001$, $\mathrm{g}_{\mathrm{p}}{ }^{2}=.10$. When providing justifications for religious nurturance vignettes 11 - to 12-year-olds $(\mathrm{M}=0.91, \mathrm{SD}=0.75)$ were more likely to make references to outcome and consequences than were 17- to 18-year-olds $(\mathrm{M}=0.28, \quad \mathrm{SD}=0.55), \quad \mathrm{F}(1$, $118)=28.22, p=.0001, g_{p}{ }^{2}=.19$. There were no significant differences between the other age groups (F values ranged from .17 to 5.33).

The second significant contrast indicated a main effect for the use of outcomes and consequences for religious self-determination vignettes, $\mathrm{F}(4,255)=4.59$, $\mathrm{p}=.001, \mathrm{~g}_{\mathrm{p}}{ }^{2}=07$. Further analysis indicated that when discussing religious self-determination vignettes, 11 - to 12-year-olds $(\mathrm{M}=0.70, \quad \mathrm{SD}=0.76)$ made more references to outcomes and consequences than did their 13- to 14-year-old counterparts $(\mathrm{M}=0.20, \mathrm{SD}=0.50), \mathrm{F}(1,100)=14.70, \mathrm{p}=.0001$, $\mathrm{g}_{\mathrm{p}}{ }^{2}=.13$. There were no significant differences between the other three age groups ( $F$ values ranged from .09 to 7.07 ).

\section{Discussion}

This study examined British adolescents' and young adults' judgments and reasoning about asylum-seeking young people's religious and nonreligious nurturance and self-determination rights, which is an issue that has received relatively little attention (Ruck et al., 2007). The findings of this study support past research on young people's judgments and reasoning about children's nurturance and self-determination rights as well as extend the extant literature in several ways. The findings are discussed in detail next, along with consideration of the implications and limitations of the present study.

\section{Domain Considerations}

As in previous research on children's and adolescents' attitudes toward children's rights (e.g., Cherney \& Perry, 1996; Cherney \& Shing, 2008; Ruck et al., 1998; Ruck et al., 2002), in the current study participants were more willing to endorse asylum-seeking adolescents' and emerging adults' nurturance than self-determination rights. Extending past research, the findings revealed that participants showed similar support for nonreligious nurturance rights and religious self-determination rights followed by somewhat less support for asylum-seeker children's religious nurturance rights. However, overall, participants showed the lowest level of support for nonreligious self-determination rights. The findings extend the domain perspective by indicating that participants were able to coordinate whether the rights invoked nurturance or selfdetermination rights with whether religious or nonreligious rights were implicated. Past research has found that children and adolescents differentiate moral and social conventional religious considerations (Nucci \& Turiel, 1993). The present findings suggest that in terms of endorsement, adolescents and young adults also differentiate nurturance and self-determination based on whether these rights include religious needs. Alternatively, the findings suggest that participants' endorsements generally followed what might be termed a hierarchy of rights. Participants endorsed secular or nonreligious nurturance rights to a greater degree than religious rights (including both religious self-determination and religious nurturance rights) and followed by secular self-determination rights.

Consistent with social cognitive domain theory and previous research (e.g., Killen, McGlothlin, \& Lee-Kim, 2002; Ruck et al., 2002; Ruck et al., 2007, Turiel, 2002, 2006) in the present study British young people employed distinct forms of reasoning when providing justifications about asylum seekers' nurturance and self-determination rights. For example, when providing justifications for the rights of asylum-seeker children, participants made appeals to issues such as parental responsibility and outcomes more for nurturance than self-determination scenarios. In addition, practical considerations were more likely to be raised in participants' discussions concerning fulfillment of asylum seekers' nurturance rights. As predicted, reasoning about asylum seekers' self-determination rights was justified by appeals to the story characters' individual's rights and personal choice. While participants were more likely to make appeals to respecting the asylum seekers' beliefs when considering religious selfdetermination rights, they were also more likely to suggest that asylum seekers should feel gratitude for being allowed in the United Kingdom when discussing secular self-determination rights. This pattern of results suggests that British adolescents and young adults are less supportive of secular 
than religious rights, especially when these rights involved self-determination.

In keeping with domain theory and research (e.g., Helwig, 1997, 2006a, 2006b; Turiel, 2002, 2006) participants' thinking also revealed the multifaceted and complex nature of social reasoning about phenomena, such as rights. Specifically, adolescents' and young adults' reasoning was sensitive to the type of vignette (nurturance, self-determination) as well as to whether the vignettes invoked religious or nonreligious rights. Indeed, different patterns of reasoning emerged for each of the four types of stories. Such findings suggest that participants' reasoning takes into account a number of different dimensions of the situation. Participants were more likely to consider practical considerations or alternatives when discussing religious nurturance vignettes than other kinds of vignettes. For example, as one 14-year-old girl remarked with regard to the vignette concerning religious dietary restrictions, "They [asylum seekers] should know that we are trying really hard to find food for them but it is not always possible to like make it perfect for every single person especially when there are many people in the world who need different things and we can't always find it." Although participants supported asylum seekers' religious rights, there were often concerns about society's obligation to be able to fulfill such rights.

Similar to past research (see Ruck et al., 2002; Ruck et al., 2007), participants were more likely to invoke appeals to parental responsibility when discussing secular nurturance vignettes than other types of vignettes. Justifying his decision that the school should not supply a uniform for an asylum seeker, one 16-year-old boy argued, "Because it's the parents' responsibility to look after children ... like buying them food and clothes." As illustrated in this example, participants in the present study clearly acknowledged the importance and obligation of parents for promoting their children's well-being.

Finally, references to the story characters' individual rights and personal choice as well as respecting the beliefs and customs of asylum-seeker children were both mentioned significantly more when discussing religious self-determination vignettes more than when discussing other types of vignettes. This finding lends further support to our earlier suggestion that possible concerns regarding the rights of asylum seekers may focus less on their religious rights than their nonreligious self-determination rights.

Our above assumption can be more clearly seen in participants' discussion of secular or nonreligious self-determination vignettes. For those scenarios participants were more likely to hold the view that asylum seekers should be indebted or grateful for being in the country. As one 16-year-old boy argued with regard to the situation of the asylum-seeker child wanting the right to choose where to live, "He shouldn't be here in the first place ... be thankful that you are in England, like in the first place, you shouldn't even be here matey, so just take it on the chin, you're staying there, and if you are lucky you will be allowed to move, otherwise go back to where you belong." It may be that for the British young people we interviewed endorsing secular self-determination rights might be interpreted as giving asylum seekers privileges or rights not warranted given their noncitizenship status or providing them with advantages not accorded to others, whereas no obvious benefit would be given for supporting religious self-determination rights. Further research is warranted to more closely examine these issues.

\section{Cultural Differences}

One of the more surprising findings was the fact young people were significantly more likely to support asylum-seeker children's religious than nonreligious rights. These results may be explained, in part, by the fact that although the United Kingdom tends to be secular in orientation (BBC News, 2004), it has a longer history of immigration from Muslim nations than other Western European countries (Ansari, 2004). In addition, recent statistics suggest that compared to other Northern European countries' attitudes toward Muslims in the United Kingdom are not nearly as negative. For example, while $51 \%$ of the Netherland population views Muslims negatively, the corresponding figure for the United Kingdom is $14 \%$ (Pew, 2005). Additionally, whereas only $19 \%$ of French and $17 \%$ of Germans endorsed the view that the hij(b is enriching to European culture, $37 \%$ of the United Kingdom endorsed this view (http://www.eumap.org/library/static/libr2/ b/2/xz5vs0u9.pdf). Thus, the United Kingdom may possibly hold more positive attitudes toward Muslim religious rights than other Western European countries.

More research comparing different European nations is clearly warranted. Much of the previous research focused on cultural differences from a domain perspective has examined whether reasoning about rights varies with the degree to which a community is collectivist or individualist (see Helwig, 2006b; Wainryb, 2006, for reviews). Generally, this dimension has not been found to influence 
participants' reasoning. Other cultural and societal factors, such as the degree to which particular nation states endorse multiculturalism or assimilation may influence participants' reasoning about the treatment of ethnic minorities. Indeed, experimental studies suggest that endorsement of assimilation compared to multiculturalism is related to negative out-group attitudes (Coenders, Lubbers, Scheepers, \& Verkuyten, 2008) and implicit and explicit prejudice (Richeson \& Nussbaum, 2004). Although the various European nation states may not differ in collectivism-individualism to a large degree (Markus \& Kitayama, 1991), they differ in attitudes toward immigrants (Mueleman, Davidov, \& Billiet, 2009). Part of these differences may result from opinions about multiculturalism and assimilation. For example, the German chancellor has gone so far as to argue that multiculturalism has "utterly failed" (The Guardian, 2010). In contrast, according to a poll conducted by the BBC News (2006), 62\% of Britons support multiculturalism. The degree to which the various nation states in the European Union support multiculturalism may influence individuals' considerations of the rights of ethnic and religious minorities and is an important area for future research.

\section{Age-Related Findings}

A number of age-related differences were found in participants' endorsements and reasoning. More specifically, the youngest participants (11-12) were more likely to endorse rights than were participants from the older age groups. An interaction effect revealed that the youngest age group was more likely to endorse same-age asylum seekers' religious nurturance and nonreligious self-determination rights than the older age groups. In contrast, the two oldest age groups (17-18 and 19-24) were less likely to affirm same-age asylum seekers' nonreligious self-determination rights, which included the right to decide where to live and the right to decide whether to carry an identification card. This last finding suggests that with increasing age, British individuals may become less tolerant of asylum seekers their own age. If this is the case, research needs to be directed at finding ways of preventing age-related increases in negative attitudes toward asylum seekers. In past research conducted in the United Kingdom, reading stories with children about refugees in which the refugee shared a common identity with the participants (e.g., being students together in the same school) reduced outgroup attitudes (Cameron et al., 2006). Whether such a procedure would increase support for asylum-seeking youth's young people's rights remains to be determined.

In contrast to past research on young people's conceptions of rights (e.g., Helwig, 1995, 1997; Ruck et al., 1998; Ruck et al., 2002), fewer age-related differences emerged in terms of reasoning than in endorsements. In the current investigation, agerelated differences were only found with regard to the justifications pertaining to "outcomes" for religious nurturance and self-determination vignettes. Specifically, the youngest participants were more likely than older participants to focus on the negative outcomes or consequences surrounding the asylum-seeker child not having his or her religious rights (nurturance or self-determination) fulfilled. Such a finding is in accord with a perspective where young children make simple appeals to the potential harmful outcomes of the situation at hand (Helwig, 1997; Ruck et al., 1998). Thus, the youngest group in the present study was more likely to endorse religious nurturance rights and to invoke outcomes as a justification than were other participants in other age groups. As one 12-year-old boy argued why an asylum-seeker should be allowed to practice his religion in a detention center, "because he would be disobeying his religion, which he wouldn't want to do because then he'd be going to a sort of hell really." However, as mentioned previously this finding was limited to those situations dealing with religious rights thus also confirming the contextual variation within participants' reasoning.

\section{Limitations and Conclusions}

There are a number of limitations of the present study that suggest possible directions for future research. First, the cross-sectional nature of the study restricts our ability to make definite statements concerning developmental differences. Longitudinal research on this topic would be useful. Second, the predominately homogenous nature of the sample severely limits the generalizability of the current findings. Future studies would benefit by more carefully considering the role of factors such as race and ethnicity as well as religiosity on young people's reasoning about the religious and nonreligious rights of asylum seekers and refugees. Third, participants rated age-matched asylum seekers. Although this may have served to increase identification with the story character and enabled participants to use better their perspective-taking skills, the design used in this study makes it impossible to untangle the age-related findings. For example, the fact that older participants were less 
willing to support same-age asylum seekers' nonreligious self-determination rights may possibly be better explained by reference to the age of the target individual rather than the age of the respondent. Future research could begin to address this age-related confound by keeping the age of the target constant so that all participants would be evaluating rights of children of the same age. Finally, studies should extend this research crossculturally to understand how national political identities may influence young people's perceptions of asylum seekers.

Despite these various limitations, the present study extends the available research on adolescents' and young adults' judgment and reasoning about rights by considering how British youth view asylum-seeking youth's religious and nonreligious rights. Future research would also benefit by considering the role of ethnic prejudice and stereotypes in how majority group youth evaluate the rights of asylum-seeking young people. The findings from such research will have important implications for better understanding intergroup relations, tolerance, and human rights. Finally, the other side of the coin should also be considered. To this end, examining young asylum seekers', immigrants', and refugees' perspectives about their own protection and self-expression rights in the United Kingdom and other host societies as well as their views concerning how they are perceived by the majority population are important research endeavors.

\section{References}

Ansari, H. (2004). The Infidel within: The history of Muslims in Britain, 1800 to the present. London: Hurst.

BBC News. (2004). UK among most secular nations. Retrieved January 5, 2010 from http://news.bbc.co.uk/ 2/hi/programmes/wtwtgod/3518375stm/

BBC News. (2006). Blair's concerns over face veils. Retrieved January 10, 2010, from http://news.bbc.co.uk/2/hi/ 6058672.stm/

Cameron, L., \& Rutland, A., (2008). An integrative approach to changing children's intergroup attitudes. In S. R. Levy \& M. Killen (Eds.), Intergroup attitudes and relations in childhood through adulthood (pp. 191-203). New York: Oxford University Press.

Cameron, L., Rutland, A., Brown, R., \& Douch, R. (2006). Changing children's intergroup attitudes towards refugees: testing different models of extended contact. Child Development, 77, 1208-1219.

Cemlyn, S., \& Briskman, L. (2003). Asylum, children's rights and social work. Child and Family Social Work, 8, 163-178.
Cherney, I., \& Perry, N. (1996). Children's attitudes toward their rights: An international perspective. In E. Verhellen (Ed.), Monitoring children's rights (pp. 241250). The Hague, Netherlands: Kluwer Law International.

Cherney, I. D., \& Shing, Y. L. (2008). Children's nurturance and self-determination rights: A cross-cultural perspective. Journal of Social Issues, 64, 835-856.

CIA World Factbook. (2006). Retrieved February 1, 2006 at http://www.cia.gov/cia/publications/factbook/

Coenders, M., Lubbers, M., Scheepers, P., \& Verkuyten, M. (2008). More than two decades of changing ethnic attitudes in the Netherlands. Journal of Social Issues, 64, 269-285.

Day, D., Peterson-Badali, M., \& Ruck, M. D. (2006). The relationship between maternal attitudes and young people's attitudes towards children's rights. Journal of Adolescence, 29, 193-207.

Demant, F., Maussen, M., \& Rath, J. (2007). Muslims in the EU: Cities Report: The Netherlands. Open Society Institute. Retrieved November 1, 2010, from http:// www.soros.org/initiatives/home/articles_publications/ publications/museucities_20080101/museucitiesnet_ 20080101.pdf

The Guardian. (2010). Angela Merkel: German multiculturalism has “utterly failed." Retrieved October 20, 2010, from http://www.guardian.co.uk/world/2010/ oct/17/angela-merkel-german-multiculturalism-failed

Helwig, C. C. (1995). Adolescents' and young adults' conceptions of civil liberties: Freedom of speech and religion. Child Development, 66, 152-166.

Helwig, C. C. (1997). The role of agent and social context in judgments of speech and religion. Child Development, 68, 484-495.

Helwig, C. C. (1998). Children' conceptions of fair government and freedom of speech. Child Development, 69, 518-531.

Helwig, C. C. (2006a). The development of personal autonomy throughout cultures. Cognitive Development, 21, 458-473.

Helwig, C. C. (2006b). Rights, civil liberties, and democracy across cultures. In M. Killen \& J. G. Smetana (Eds.), Handbook of moral development (pp. 185-210). Mahwah, NJ: Erlbaum.

Helwig, C. C., \& Turiel, E. (2002). Rights, autonomy, and democracy: Children's perspectives. International Journal of Law and Psychiatry, 25, 253-270.

Home Office. (2007). Life in the UK: A guide to citizenship. Norwich, UK: Her Majesty’s Stationery Office.

Hussain, S., \& Choudhoury, T. (2007). Muslims in the EU: Cities Report: UK. Open Society Institute, Retrieved November 1, 2010, from http://www.soros. org/initiatives/home/articles_publications/publications/ museucities_20080101/museucitiesuk_20080101.pdf

Jones, A. (2001). Child asylum seekers and refugees: Rights and responsibilities. Journal of Social Work, 1, 253-271.

Killen, M., McGlothlin, H, \& Lee-Kim, J. (2002). Between individuals and culture: Individuals' evaluations of 
exclusion from social groups. In H. Keller, Y. Poortinga, \& A. Schoelmerich (Eds.), Between biology and culture: Perspectives on ontogenetic development (pp. 151-190). Cambridge, UK: Cambridge University Press.

Lahat, A., Helwig, C., Yang, G., Tan, D., \& Liu, C. (2009). Mainland Chinese adolescents' judgments and reasoning about self-determination and nurturance rights. Social Development, 18, 690-710.

Lynch, M. A., \& Cunninghame, C. (2000). Understanding the needs of young asylum seekers. Archives Diseases of Childhood, 83, 384-387.

Markus, H. R., \& Kitayama, S. (1991). Culture and the self: Implications for cognition, emotion, and motivation. Psychological Review, 98, 224-253.

Meuleman, B., Davidov, E., \& Billiet, J. (2009). Changing attitudes toward immigration in Europe, 2002-2007: A dynamic group conflict theory approach. Social Science Research, 38, 352-365.

Møller, S. J., \& Tenenbaum, H. (2011). Danish majority children's reasoning about exclusion based on gender and ethnicity. Child Development, 82, 520-532.

MORI. (2003). British views of immigration. London: Author.

Neuberger, J. (2005). The moral state we're in: A manifesto for a 21st century society. London: HarperCollins.

Nucci, L., \& Turiel, E. (1993). God's word, religious rules and their relation to Chrisitian and Jewish children's concepts of morality. Child Development, 64, 1485-1491.

Peterson-Badali, M., Morine, S., Ruck, M., \& Slonim, N. (2004). Predictors of maternal and child attitudes towards children's nurturance and self-determination rights. Journal of Early Adolescence, 24, 159-179.

Peterson-Badali, M., \& Ruck, M. D. (2008). Studying children's perspectives on self-determination and nurturance rights: Issues and challenges. Journal of Social Issues, 64, 749-769.

Richeson, J. A., \& Nussbaum, R. J. (2004). The impact of multiculturalism versus color-blindness on racial bias. Journal of Experimental Social Psychology, 40, 417-423.

Ruck, M. D., Abramovitch, R., \& Keating, D. (1998). Children's and adolescents' understanding of rights: Balancing nurturance and self-determination. Child Development, 64, 404-417.

Ruck, M. D., \& Horn, S. S. (2008). Charting the landscape of children's rights. Journal of Social Issues, 64, 685-700.

Ruck, M. D., \& Peterson-Badali, M. (2006). Youths' perceptions of rights. In L. R. Sherrod, C. Flanagan, \& R. Kassimir (Eds.), Youth activism: An international encyclopedia (pp. 535-539). Westport, CT: Greenwood.
Ruck, M. D., Peterson-Badali, M., \& Day, D. (2002). Adolescents' and mothers' understanding of children's rights in the home. Journal of Research on Adolescence, 12, 373-398.

Ruck, M. D., Tenenbaum, H., \& Sines, J. (2007). Brief report: British adolescents' views about the rights of asylum-seeker children. Journal of Adolescence, 30, 687-693.

Ruck, M. D., Tenenbaum, H. R., \& Willenberg, I. (2011). South African mixed-race children's and mothers' judgments and reasoning about children's nurturance and self-determination rights. Social Development, 20, 431643.

Smetana, J. G. (2006). Social domain theory: Consistencies and variations in children's moral and social judgments. In M. Killen \& J. G. Smetana (Eds.), Handbook of moral development (pp. 119-154). Mahwah, NJ: Erlbaum.

Tempest, M. (2004). ID cards will not stop terrorism. Guardian Online. Retrieved April 18, 2011 from http://www.guardian.co.uk/world/2004/apr/27/september11.usa

Turiel, E. (2002). The culture of morality. Cambridge, England: Cambridge University Press.

Turiel, E. (2006). The development of morality. In W. Damon \& N. Eisenberg (Eds.), Handbook of child psychology: Social, emotional and personality development (6th ed., Vol. 3, pp. 863-932). New York: Wiley.

Turiel, E., \& Wainryb, C. (1998). Concepts of freedoms and rights in a traditional, hierarchically-organized society. British Journal of Developmental Psychology, 16, 375-395.

United Nations General Assembly. (1989). Adoption of a convention on the rights of the child. New York: Author.

Verkuyten, M., \& Slooter, L. (2007). Tolerance of Muslim beliefs and practices: Age related differences and context effects. International Journal of Behavioral Development, 31, 467-477.

Verkuyten, M., \& Slooter, L. (2008). Muslim and nonMuslim adolescents' reasoning about freedom of speech and minority rights. Child Development, 79, 514528.

Verkuyten, M., \& Steenhuis, A. (2005). Preadolescents' understanding and reasoning about asylum seeker peers and friendships. Applied Developmental Psychology, 26, 660-679.

Wainryb, C. (2006). Moral development in culture: Diversity, tolerance, and justice. In M. Killen \& J. Smetana (Eds.), Handbook of moral development (pp. 211-240). Mahwah, NJ: Erlbaum.

YouGov/Mail on Sunday. (2004). YouGov/Mail on Sunday Survey. London: YouGov. 